\title{
Impact of grazing, resource availability and light on prokaryotic growth and diversity in the oligotrophic surface global ocean
}

\author{
by
}

\author{
Eva Teira ${ }^{1}$, Ramiro Logares ${ }^{2}$, Alberto Gutiérrez-Barral ${ }^{1}$, Isabel Ferrera ${ }^{2,3}$, Marta M. \\ Varela $^{4}$, Xosé Anxelu G. Morán ${ }^{5}$ Josep M. Gasol ${ }^{2,6}$
}

(1) Dpt. Ecoloxía e Bioloxía Animal, Universidade de Vigo, Vigo, Spain

(2) Dpt. Biologia Marina i Oceanografia, Institut de Ciències del Mar, CSIC;

Barcelona, Catalonia, Spain

(3) Instituto Español de Oceanografía, Centro Oceanográfico de Málaga, Fuengirola, Spain

(4) Instituto Español de Oceanografía, Centro Oceanográfico de A Coruña, A Coruña, Spain

(5) Red Sea Research Center, Division of Biological and Environmental Sciences and Engineering, King Abdullah University of Science and Technology, Thuwal, Saudi Arabia

(6) Centre for Marine Ecosystems Research. Edith Cowan University, Joondalup, WA Australia

\section{Corresponding author:}

Eva Teira

Biological Oceanography Group

Torre Nuevo CACTI, Lab. 100

Campus Universitario Lagoas-Marcosende

C.P.: 36310 Vigo (Pontevedra), Spain

Tel.: (+34)986818791

This article has been accepted for publication and undergone full peer review but has not been through the copyediting, typesetting, pagination and proofreading process which may lead to differences between this version and the Version of Record. Please cite this article as doi: 10.1111/1462-2920.14581

This article is protected by copyright. All rights reserved. 
e-mail: teira@uvigo.es

Running title: Impact of grazing, resources and light on prokaryotes

Keywords: Prokaryotes, growth, diversity, grazing, resources, light, oligotrophic global ocean

\section{Originality-Significance Statement:}

We manipulated natural microbial communities in order to get insight into what controls growth and community composition of prokaryotes in the global oligotrophic ocean. The reduction of grazing pressure, by itself, essentially caused an increase in prokaryotic growth and a moderate decrease in community richness, while the increase in resource availability, by itself, enhanced growth at the level of community but systematically reduced populations of well-known oligotrophic taxa such as SAR11 and Prochlorococcus. By contrast, light exposure did not result in a significant re-structuration of the prokaryotic community. There was, however, an overall negative effect of light exposure on growth rates and community richness which, interestingly, seemed to be related to a poor acclimation of prokaryotic communities to the high incident irradiances associated to relatively deep mixed layers.

\section{Summary}

The impact of grazing, resource competition and light on prokaryotic growth and taxonomic composition in subtropical and tropical surface waters was studied through 10 microcosm experiments conducted between $30^{\circ} \mathrm{N}$ and $30^{\circ} \mathrm{S}$ in the Atlantic, Pacific and Indian oceans. Under natural sunlight conditions, significant changes in taxonomic composition were only observed after the reduction of grazing by sample filtration in 
combination with a decrease in resource competition by sample dilution. Sunlight exposure significantly reduced prokaryote growth $(11 \pm 6 \%)$ and community richness $(14 \pm 4 \%)$ compared to continuous darkness but did not significantly change community composition. The largest growth inhibition after sunlight exposure occurred at locations showing deep mixed layers. The reduction of grazing had an expected and significant positive effect on growth, but caused a significant decrease in community richness $(16 \pm 6 \%)$, suggesting that the coexistence of many different OTUs is partly promoted by the presence of predators. Dilution of the grazer-free prokaryotic community significantly enhanced growth at the level of community, but consistently and sharply reduced the abundance of Prochlorococcus and SAR11 populations. The decline of these oligotrophic bacterial taxa following an increase in resource availability is consistent with their high specialization for exploiting the limited resources available in the oligotrophic warm ocean.

\section{Introduction}

The abundance and impact of marine microbes on biogeochemical processes depend on the balance between their growth and mortality rates (Strom, 2008; Kirchman, 2016). The growth rates of prokaryotes living in the pelagic realm are largely limited by the availability of inorganic nutrients and/or organic carbon (Carlson and Ducklow, 1996; Caron et al., 2000; Martínez-Garcia et al., 2010; Hale et a.1, 2017), while the main sources of mortality are viral lysis and grazing by protists (Fuhrman and Noble, 1995; Pernthaler, 2005; Kirchman, 2016). Besides controlling the standing stock of prokaryotic communities, 
predators and viruses may also affect community composition likely through selective grazing and host specificity (Jürgens and Matz, 2002; Pernthaler, 2005; Corno and Jürgens,2008; Cram et al., 2016), although some theoretical models predict that protistan predation should have little effect on bacterial community composition (Thingstad and Lignell 1997; Thingstad, 2000). An experimental study by Baltar et al. (2016) concluded that protist predation does not significantly alter bacterioplankton community composition in the Mediterranean Sea. Depending on the environmental characteristics, microbial communities may be controlled by bottom-up factors (i.e. nutrient availability), top-down factors (grazing or viral lysis), as well as by temperature (Sunagawa et al., 2015; Morán et al., 2017) and light (Ruiz-González et al., 2013; Richert et al., 2015, Sánchez et al., 2017) in a changing balance. In oligotrophic waters, it has been suggested that bacterial abundance and production are fundamentally determined by nutrient supply (Sanders et al., 1992), whereas other authors have found that grazing pressure on bacteria is also a relevant regulatory factor (Caron et al., 2000; Gasol et al., 2002; Silva et al., 2019).

Compared to the role of nutrients and predators on microbial dynamics, the effect of light on prokaryotes has only been extensively studied in the last two decades (see review by Ruiz-González et al., 2013). Sunlight affects marine prokaryotes in different ways: some organisms, such as cyanobacteria, need light for survival as well as for growth, others, such as the aerobic anoxygenic phototrophic (AAP) bacteria or proteorhodopsin-containing organisms, are stimulated by light (Kolber et al., 2000; Bejá et al., 2001; Gómez-Consarnau et al., 2007; Straza and Kirchman, 2011, Ferrera et al. , 2017), and others, such as members 
of the SAR11 clade, can be sensitive to solar UV radiation (Alonso-Sáez et al., 2006; RuizGonzález et al., 2012, Matallana-Surget et al., 2012). These multiple effects are likely to translate into complex prokaryotic community responses to variations in sunlight exposure (Langenheder et al., 2006; Manrique et al., 2012; Richert et al., 2015). The magnitude of such alterations probably depends not only on the spectral quality and intensity of the incident radiation but also on nutrient availability (Morán et al. 2001) and the previous light exposure history, both largely modulated by water column vertical mixing (Bertoni et al., 2011; Matallana-Surget et al., 2012; Ruiz-González et al., 2012; 2013, Galí et al., 2013).

To the best of our knowledge, the experimental assessment of the importance of top-down and bottom-up controls jointly with light as regulating factors of prokaryotic community composition and growth, has not been systematically assessed in the oligotrophic surface ocean. The permanent stratification of tropical and subtropical oceans reduces nutrient supply to the upper layers (Longhurst, 2010), originating a large nutrientdepleted habitat where light intensity and depth penetration are large (Tedetti and Sempéré, 2006). These conditions favor the selection of oligotrophic (Lauro et al., 2009; Overmann and Lepleux, 2016), and high-irradiance acclimated taxa (Alonso-Saez et al., 2006; Kataoka et al., 2009; Santos et al., 2011; Ruiz-Gonzalez et al., 2012, 2013). Pelagibacter (SAR11) and Prochlorococcus are two well-known genera representative of the oligotrophic lifestyle (Overmann and Lepleux, 2016). These two genera typically dominate the surface waters of tropical and subtropical oceanic biomes (Partensky et al., 1999; Morris et al., 2002) and share a set of adaptations, such as the ability to exploit light and 
small cell and genome sizes, allowing them to thrive in extremely diluted and illuminated environments (Biller et al., 2015; Giovanonni, 2017).

To evaluate the importance of top-down and bottom-up controls as well as solar radiation on prokaryotic growth and taxonomic community composition in surface waters of the tropical and subtropical oceans, we conducted microcosm experiments at 10 stations located between $30^{\circ} \mathrm{N}$ and $30^{\circ} \mathrm{S}$ in the Atlantic (4 experiments), Pacific (4 experiments) and Indian (2 experiments) oceans from December 2010 to June 2011. We manipulated grazing pressure through $0.8 \mu \mathrm{m}$ sample filtration, resource availability through dilution of the filtered samples with $0.2 \mu \mathrm{m}$ filtered seawater, and solar radiation by exposing filtered and diluted samples either to the natural full sunlight spectrum or to total darkness. Growth rates at the community level were estimated from biomass and production data, while community composition was explored using high-throughput $16 \mathrm{~S}$ rRNA amplicon sequencing. We hypothesize that resource competition and solar radiation are key determinants of community composition, while grazing mostly affects growth of prokaryotes inhabiting these regions.

\section{Results}

\section{Initial conditions}

Seawater for the experiments was collected from $3 \mathrm{~m}$ depth at 10 sampling sites (Fig. 1a). A relatively wide range of initial conditions was observed at the sampling sites for the measured environmental variables (Table 1). Chlorophyll- $a$ concentration ranged from 0.03 
$\mu \mathrm{g} \mathrm{L}^{-1}$ in the South Atlantic (station 3) to $0.21 \mu \mathrm{g} \mathrm{L}^{-1}$ in the western tropical Pacific (station 9) (Table 1). Phosphate concentration also varied 10-fold from $0.02 \mu \mathrm{mol} \mathrm{L}^{-1}$ in the Indian Ocean to $0.32 \mu \mathrm{mol} \mathrm{L} \mathrm{L}^{-1}$ in the equatorial Pacific (Table 1). By contrast, nitrate concentrations varied two orders of magnitude, from $0.03 \mu \mathrm{mol} \mathrm{L}^{-1}$ in the North Pacific to $2.28 \mu \mathrm{mol} \mathrm{L} \mathrm{L}^{-1}$ in the equatorial Pacific (Table 1). Heterotrophic prokaryotic abundance varied by ca. one order of magnitude (Table 1) and was highest in the North Atlantic (station 2). The mixed layer depth (MLD) varied largely from as shallow as $8 \mathrm{~m}$ in the North Atlantic (station 1) to $100 \mathrm{~m}$ in North Pacific (station 8).

There were no significant differences in the initial prokaryotic assemblages among experiments or ocean basins (Fig. $1 \mathrm{~b}$ ) (Permutation test, $\mathrm{p}>0.05$ ). The initial prokaryotic communities were dominated by Subsection I Cyanobacteria and the SAR11 clade representing, on average, $51 \%$ and $16 \%$ of the $16 \mathrm{~S}$ rRNA-gene sequences, respectively (Fig. 1b). The lowest richness, Shannon diversity index (H') and Pielou evenness index (J') corresponded to station 5, in the Indian ocean, where phosphate concentration was also the lowest (Table 1), and the community was overwhelmingly dominated by subsection I cyanobacteria and SAR11 clade, jointly representing $88 \%$ of the reads (Fig. 1b). Prochlorococcus was the dominant cyanobacterial taxon (representing $>90 \%$ of the cyanobacterial sequences) in all stations, excepting stations 1 and 9, where Synechococcus contributed $37 \%$ and $90 \%$, respectively, to the pool of cyanobacterial sequences (details not shown). The relative abundance of the SAR11 clade was comparatively low in the eastern 
tropical North Pacific (station 9), and eastern tropical North Atlantic (station 1), coinciding with the shallowest MLD (Table 1). The contribution of archaea to the prokaryotic community was systematically low, contributing, on average, $<1 \%$ of total sequence abundance.

\section{Effect of grazing, dilution and light exposure on prokaryotic growth}

The estimated growth rates at time zero were $<0.3 \mathrm{~d}^{-1}$ except in the equatorial Pacific, where initial rates were ca. $2 \mathrm{~d}^{-1}$ (Fig. S1). An appreciable increase in prokaryotic growth rate over the first $24 \mathrm{~h}$ of incubation in unmanipulated surface seawater exposed to light (thereafter LC treatment) was observed in 7 out of 10 experiments (Fig. S1). Maximum growth rates mostly occurred in the filtered and diluted treatments exposed to light (thereafter LFD treatment) or darkness (thereafter DFD treatment).

In order to summarize the effect of the different treatments, we calculated the effect of filtration (light filtered to light control, LF/LC response ratio), the effect of dilution (light filtered diluted to light filtered, LFD/LF response ratio) and the effect of light on the filtered and diluted samples (light filtered diluted to dark filtered diluted, LFD/DFD response ratio) by averaging the response ratios derived for each time point (Fig. 2). A significant positive effect of filtration on growth rates was observed in 5 out of 10 experiments (Wilcoxon test, $\mathrm{p}<0.05$ ), while dilution enhanced prokaryotic growth rates in 2 out of 10 experiments (Wilcoxon test, $\mathrm{p}<0.05$ ) (Fig. 2). Interestingly, dilution caused a significant decrease in growth rates in experiment 3 (South Atlantic Ocean), and 
experiment 7 (equatorial Pacific Ocean) (Wilcoxon test, p<0.05) (Fig 2). Light exposure significantly reduced growth in 3 out of 10 experiments conducted in the equatorial and North Atlantic and Pacific Oceans (Wilcoxon test, $\mathrm{p}<0.05$ ) (Fig 2). The magnitude of growth inhibition by light was significantly correlated with the mixed layer depth (Table S1), the deeper the MLD, the higher the inhibition (Fig 3).

When pooling the response ratios of the 10 experiments growth rates, on average significantly increased 3.1-fold after filtration (Z-test, $\mathrm{p}=0.011$ ), and 1.7-fold (Z-test, $\mathrm{p}=0.022)$ after dilution; and decreased 0.9-fold upon light exposure (Z-test, $\mathrm{p}=0.025)$ (Fig. 4). The magnitude of the increase in prokaryotic growth associated to grazing reduction was positively correlated with the initial prokaryote abundance (Table S1)

Effect of filtration, dilution and light exposure on bacterial community composition and diversity

Based on the time-course changes in growth (Fig. S1), we infer that shifts in community composition mostly occurred within the first $24-48 \mathrm{~h}$, and that the prokaryotic community remained relatively stable afterwards. The most noticeable alteration after $72 \mathrm{~h}$ of incubation associated to the combination of filtration and dilution (LFD versus LC) was the consistent and sharp decrease in the relative abundance of cyanobacterial and/or SAR11 reads (Fig. 5), which resulted in significant differences in community composition (Fig. 6) (Permutation test, $\mathrm{p}=0.013$ ). There was a significant effect of the sample origin on the final community composition (Fig. 6) (Permutation test, $\mathrm{p}<0.001$ ). Filtration alone (LF versus 
LC) did not cause significant changes in community composition (Permutation test, $\mathrm{p}=0.570$ ) (Fig. 6), favoring different groups depending on the origin of the sample, like Rhodobacterales (experiments 1-N-Atl and 2-Eq-Atl), Flavobacteriales (experiment 4-SInd), Alteromonadales (experiments 1-N-Atl, 2-Eq-Atl, 8-N-Pac) or Caulobacterales (experiment 3-S-Atl) (Fig. 5). On the other hand, the dilution of filtered samples (LFD versus LF) eventually favored or hindered a particular group (Fig. 5), but did not globally cause significant changes (Permutation test, $\mathrm{p}=0.164$ ) (Fig. 6). The effect of light exposure (LFD versus DFD) on prokaryotic community composition was not significant (Permutation test, $\mathrm{p}=0.979$ ) (Figs. 5, 6). On average, OTU richness at the end of the experimental incubation, significantly decreased after filtration (0.83-fold) and light exposure (0.85-fold) (Table S2, Fig. 4). Shannon diversity and Pielou evenness significantly decreased with filtration ca. 0.9-fold (Table S2, Fig 4). The decrease in richness associated to filtration was positively correlated with the initial nitrate concentration, while that associated to dilution was negatively related with phosphate concentration (Table S1).

Effect of filtration and dilution on the relative abundance of specific OTUs

A differential analysis of the sequence abundance data, as implemented in DESeq2, detected nine differentially abundant OTUs $(\mathrm{p}<0.045, \mathrm{FDR}<0.1)$ associated with the filtration treatment (i.e. LC versus LF treatment) (Fig. 7a). The same analysis detected eight differentially abundant OTUs associated with the dilution treatment (i.e. LF versus LFD 
treatment) (Fig. 7b). By contrast, none of the OTUs showed a significant difference in abundance when comparing LFD versus DFD ( $p>0.02, F D R>0.32)$. The sequences of two Rhodobacterales OTUs showed a positive effect of filtration increasing their abundance in the LF treatment compared to the LC by up to 6-fold (Fig 7a). An alphaproteobacterium belonging to the Thalassospira genus, showing a relatively low abundance in the LC treatment, also significantly increased its abundance upon filtration. Several other OTUs showing low to moderate abundances in the LC treatment and belonging to different bacterial taxa were negatively affected by filtration (Fig. 7a). The dilution of the grazer-free community favored the increase in the abundance of two Rhodobacterales OTUs, affiliated to genera Marinovum and Maritimibacter, and a Caulobacterales OTU affiliated to the genus Hyphomonas (Fig. 7b). Notably, the dilution negatively affected two OTUs that were abundant in the LF treatment, including a Prochlorococcus OTU (representing on average 90\% of total Prochlorococcus abundance), and a SAR11 OTU (representing on average 93\% of total SAR11 abundance) (Fig. 7). A less abundant SAR11 OTU, an alphaproteobacterium OTU affiliated to the Sphingobium genus, and a Flavobacteriales OTU affiliated to the NS2b group also showed a reduction in sequence abundance upon dilution (Fig. 7b).

\section{Discussion}

Methodological considerations 
We manipulated natural microbial communities from surface waters of the global subtropical and tropical ocean in order to get insight into what controls prokaryote growth and community composition in these well-illuminated, mostly oligotrophic regions comprising $70 \%$ of the ocean's surface. It is important to note that the filtration and dilution procedures aimed at exploring the effect of grazing and resource availability have some limitations (Gasol and Morán, 1999; Fuchs et al., 2000). Regarding filtration, for example, some predators may pass through the filter pores, and even though grazing pressure is undoubtedly reduced, it is not wholly eliminated. Filtration also excludes larger particles and cells, including primary producers, which may cause a reduction of resource availability during the incubation as compared to the unmanipulated control, and thus the impact of reducing grazing pressure on growth can be underestimated. Filtration may also cause cell breakage and release dissolved substances not present in the unmanipulated seawater, which may compensate for the aforementioned resource reduction. Moreover, the filtered and diluted treatment would most likely result in an increase in resource availability as compared to the filtered treatment, just because a similar amount of nutrients would be available for only $1 / 5^{\text {th }}$ of the original prokaryotic community (Fuchs et al., 2000), thus relaxing competition. However, we must notice here that an accompanying consequence of dilution with $0.2 \mu \mathrm{m}$ filtered seawater is the increase in the virus to prokaryotes ratio. Consequently, we cannot discard an increase in prokaryotic cell lysis (Wilcox and Fuhrman, 1994, Larsen et al., 2004) in the filtered and diluted treatment compared with the filtered treatment, which would also underestimate the impact of 
resource availability on prokaryotes. Considering all these constraints, our conclusions would be on the conservative side concerning the effect of grazing and resource availability reduction.

Role of acclimation in the response of prokaryotes to light exposure

On average, the impact of light exposure on prokaryotic growth in our study was moderately low as previously observed in coastal waters of the Southern Ocean (Richert et al., 2015) or the Mediterranean Sea (Sánchez et al., 2017). The overall negative effect (Fig. 4) was mostly driven by the sharp negative impact observed in one of the North Pacific experiments (Fig. 2), associated with a very deep mixed layer depth (MLD) (Fig. 3). Such pattern strongly suggests that the ability of prokaryotes inhabiting the surface layers of the oceans to stand high levels of solar radiation depends on their previous exposure to radiation (see Bertoni et al., 2011; Ruiz-González et al., 2013; and references therein). The MLD influences the average light (including both PAR and UVR) exposure, and relates to the rate of vertical transport, which determines the residence time of a given organism within the zone of exposure to damaging radiation (Neale et al., 2003). In this regard, deep mixed layers would likely result in microorganisms staying for very short periods on the high radiation exposure zone as to photoacclimate. We clearly show that some prokaryotes in North and Equatorial Atlantic and Pacific waters were not able to cope with increased sunlight during 3 days of exposure at the high irradiance intensities associated to on-deck incubations. 
Although light exposure caused a slight decrease in prokaryotic richness (Fig. 4), it had no significant effects on prokaryotic community composition during the experiments (Figs. 5, 6), as previously reported for other marine sites (Winter et al., 2001; Schwalbach et al., 2005; Piquet et al., 2010). Unexpectedly, cyanobacterial taxa did not show a significant response to light exposure, suggesting that they are able to survive in dark conditions, at least for short periods, conceivably owing to their ability to use organic substrates (Zubkov et al., 2003; Scanlan et al., 2009; Muñoz-Marín et al., 2013). Schwalbach et al. (2005) found a sharp decline in cyanobacterial taxa abundance during longer incubations (5-10 days) in total darkness. With the only exception of an experiment in the South Indian Ocean, the contribution of Rhodobacterales to the prokaryotic community was similar or higher in the LFD than in the DFD treatments (Fig. 5). This is consistent with the capability for aerobic anoxygenic photosynthesis (AAP) present in many representatives within this group (Buchan et al., 2005; Wagner-Döbler and Biebl, 2006; Moran et al 2007; Brinkhoff et al., 2008). Experimental studies have demonstrated that members of the Roseobacter clade benefit from light exposure (Alonso-Sáez et al., 2006, Ruiz-González et al., 2012; Sánchez et al., 2017).

\section{Grazing pressure favors prokaryotic diversity}

Grazing reduction promoted an expected significant increase in prokaryotic growth (Fig. 2,

Fig. 4), in accordance with the previously suggested bacterial growth top-down control under oligotrophic conditions (Caron et al., 2000; Gasol et al., 2002; Pernthaler, 2005, Silva 
et al., 2019). Consistent with theoretical models (Thingstad and Lignell, 1997; Thingstad, 2000), experimental data (e.g. Richert et al., 2015; Baltar et al., 2016) and field observations (e.g. Storesund et al., 2016), grazing appears to have a limited influence on the community composition in our experiments (Figs. 5,6). This is in contrast with empirical evidence of a large impact of predators on prokaryotic community structure in freshwater ecosystems (e.g, Simek et al., 2001; Pernthaler et al., 2001), which supports the notion that the magnitude of the influence of predation on prokaryotes depends on the characteristics of the system (Pernthaler, 2005; Corno and Jürgens, 2008). Comparatively, more consensus exists about the positive role of predation on prokaryotic richness (Pernthaler, 2005; Zhang et al., 2007; Corno and Jürgens, 2008; Ram et al., 2016). Here, we also found a significant reduction in prokaryotic richness (ca. 20\%), Shannon diversity (ca. 17\%) and evenness (ca. $10 \%$ ) when predators were removed (LF versus LC) (Fig. 4). The abundance of prokaryotes in the LF treatment did not significantly differ from that in the LC (paired T-Test, $\mathrm{p}=0.06$ ) at the beginning of the experimental incubation, which strongly supports that the observed decrease in richness is not associated to the potential exclusion of large prokaryote cells by filtration. This effect on richness might be related to the top-down control of fast-growing opportunistic taxa by grazers (Pernthaler, 2005). The significant increase, after grazing reduction, of populations belonging to Rhodobactereaceae, the Roseobacter clade (i.e. Thalassococcus genus) and Thalassospira (Fig. 7a), known to include fast-growing or copiotrophic bacteria (Allers et al., 2007; Teira et al., 2009; Ferrera et al., 2011, Hütz et al., 2011; Teira et al., 2011) is coherent with this hypothesis. The bacterial taxa negatively 
affected by filtration, such as OM60 (NOR5) Gammaproteobacteria or Prochlorococcus (Fig. 7a), would likely be outcompeted by fast-growing species once grazer abundance is reduced by filtration. Moreover, the decrease in richness associated to grazing reduction was higher when nitrate concentration was higher (Table S1), which would favor phylotypes adapted to rapid growth when nutrient concentrations are high. Once freed from top-down control, these fast-growing bacteria would outcompete grazing-resistant, but slow-growing bacteria resulting in an overall decrease of richness. Accordingly, grazing would act as a key force sustaining richness in these oligotrophic systems, by favoring slow-growing or oligotrophic lineages and, consequently, diminishing competitive exclusion (Zhang et al., 2007; Gifford et al., 2013). A recent review on adaptations of oligotrophic bacteria highlights their characteristically low loss rates by top-down agents such as protistan grazers or viruses (Overmann and Lepleux, 2016; and references therein).

Increase in resource availability negatively affects oligotrophic bacteria

Prokaryotic community composition significantly changed, as compared to the unmanipulated control (LC), only in the filtered and diluted (LFD) treatment, suggesting that both top-down and bottom-up forces contribute to shape prokaryotic assemblages in surface oligotrophic waters. Interestingly, neither community composition nor richness were significantly affected by the dilution itself (LFD vs LF) (Figs. 4,6), which implies that, paradoxically, resource availability alone has a relevant but limited role in controlling prokaryotic communities in the oligotrophic ocean as previously concluded from both 
empirical data (Strom, 2000; Gasol et al., 2002) and theoretical models (Thingstad and Lignell, 1997). It is important to note that the total amount of resources was not manipulated here; we only modified its availability by reducing prokaryotic abundance through dilution. To our knowledge, this is the first experimental study where the effect of resource availability on prokaryotic populations has been systematically assessed by combining filtered (i.e., grazer-free) and diluted seawater short-term incubations with high throughput sequencing analyses in the oligotrophic ocean. Even though our resource manipulation caused only minor changes at the community level, significant changes could be appreciated at the level of individual OTUs (Fig. 7b). The relative sequence abundance of the two most abundant populations, assigned to the SAR11 clade (on average, $12 \%$ of total sequences in unmanipulated samples) and the genus Prochlorococcus (on average, $11 \%$ of total sequences in unmanipulated samples), decreased ca. 4 and ca. 9-fold respectively, in the filtered and diluted (LFD), compared to the filtered treatment (LF). Calvo-Díaz et al. (2011) had also observed a decrease in Prochlorococcus abundance accompanied by an increase in heterotrophic bacteria during short-term bottle incubations. These authors speculated that, among other factors, the potential increase in the availability of substrates due to seawater manipulation could favor heterotrophic versus autotrophic prokaryotes. In the same line, previous experiments with surface seawater in the Atlantic Ocean revealed systematic negative responses of SAR11 bacteria to the addition of organic nutrients, alone or combined with inorganic nutrients, suggesting that they might be outcompeted by other fast-growing bacteria upon enrichment (Teira et al., 2010). By 
contrast, other experimental studies did not observe a decrease in SAR11 abundance after dilution of non-filtered (i.e. grazers are present) seawater (Ferrera et al., 2011; Cram et al., 2016), which may be explained by the tight control exerted by grazers on fast-growing bacteria.

Both SAR11 and Prochlorococcus are well known representatives of the oligotrophic lifestyle in the marine realm (Overmann and Lepleux, 2016). A member of the Sphingobium genus was also negatively affected by dilution (Fig. 7b), which agrees with the widespread adaptation of sphingomonads to oligotrophic environments (Lauro et al., 2009; Aylward et al., 2013). Oligotrophic bacteria are typically very abundant and exhibit a series of adaptations that allow them to succeed in very diluted environments, including their small sizes, streamlined genomes, high grazing and viral infection resistance, or slow but constant growth irrespective of substrate concentration (Cottrell and Kirchman, 2016; Overmann and Lepleux, 2016; Dadon-Pilosof et al., 2017). In addition, oligotrophic bacteria present a reduced transcriptional control compared to copiotrophic bacteria that preclude them to sense and react to environmental fluctuations (Lauro et al., 2009; Gifford et al., 2013; Cottrell and Kirchman, 2016; Overmann and Lepleux, 2016). Our data nicely agree with such diverging trophic strategies. The increase in resource availability associated to dilution favored copiotrophic bacteria adapted to respond to perturbations (Fig. 7b), such as the Rhodobacterales Maritimibacter and Marinovum or the Caulobacterales Hyphomonas (Brinkhoff et al., 2008; Hogle et al., 2016), which would presumably 
outcompete oligotrophic populations. A less abundant member of the Flavobacteria-NS2b marine group (on average, $0.3 \%$ of the sequences in the unmanipulated samples) could also have an oligotrophic lifestyle, as it showed a ca. 5-fold decrease in sequence abundance after dilution (Fig. 7b). Although there is not much information about the ecology of the NS2b marine group, Alonso-Sáez et al. (2015) showed that this bacterial group follows similar temporal dynamics than SAR11 populations, which suggests that it may also be well adapted to oligotrophic conditions. Korlevic et al. (2015) also suggested that the Flavobacteria-NS2b clade could be adapted to oligotrophic conditions in an extensive study in the Adriatic Sea.

\section{Conclusion}

The manipulation of natural microbial communities from surface waters of the global subtropical and tropical ocean revealed an overall negative effect of light exposure on growth rates and community richness which, interestingly, seems to be related to a poor acclimation of prokaryotic communities to high incident irradiances associated to relatively deep mixed layers. By contrast, light exposure did not result in a significant re-structuring of the prokaryotic community. The reduction of grazing pressure by itself caused essentially an increase in prokaryotic growth and a moderate decrease in community richness, Shannon diversity and evenness, while the increase in resources alone enhanced growth at the level of community and systematically reduced populations of well-known oligotrophic taxa such as SAR11 and Prochlorococcus. The responses to dilution of grazer- 
free prokaryotic communities described here, strongly suggest that a reduction in resource competition in the absence of predators may negatively affect prokaryotic lineages well adapted to the oligotrophic growth conditions prevailing in the surface ocean

\section{Experimental procedures}

Sample collection and experimental setup.

Experiments were carried out at 10 stations located in the tropical and subtropical Atlantic, Indian and Pacific oceans between 14th December 2010 and 14th July 2011, during the Malaspina 2010 circumnavigation expedition (http://www.expedicionmalaspina.es/), on board the R/V Hespérides (Figure 1a). Conductivity-Temperature-Depth (CTD) casts were carried out at each station with a Sea-Bird Electronics 911 plus probe attached to a rosette equipped with Niskin bottles starting around 10:00 local time. Profiles of underwater photosynthetically active radiation (PAR) were obtained with a $4 \pi$ Biospherical QCP2300HP sensor attached to the CTD. At each sampling site seawater samples were taken a $3 \mathrm{~m}$ depth for chemical (nutrients, chlorophyll-a concentrations) and biological (heterotrophic prokaryotic abundance, prokaryotic community taxonomic composition) characterization as part of the Malaspina sampling routine. Samples for phosphate and nitrate measurements were frozen and their concentrations were determined by standard colorimetric methods with a Technicon autoanalyzer (Cabello et al 2016). Chlorophyll-a concentration was 
fluorometrically determined after biomass concentration onto $0.2 \mu \mathrm{m}$ pore size polycarbonate filters and extraction in $90 \%$ acetone (Estrada et al 2016). The mixed layer depth was estimated as the depth where local potential density exceeded by $0.1 \mathrm{~kg} \mathrm{~m}^{-3}$ the value of the shallowest data point and obtained from Fernández-Castro et al., (2014).

\section{Experimental setup}

Seawater for the experiments was collected from $3 \mathrm{~m}$ depth using 30-L Niskin bottles and filtered through a $200 \mu \mathrm{m}$ mesh to remove large zooplankton. Ultraviolet (UVA and UVB) radiation transparent 3-L carboys made of low density polyethylene were used for the incubations. Each experiment consisted of 3 treatments (in duplicate): a filtered treatment through $0.8 \mu \mathrm{m}$ pore size polycarbonate filters to reduce predators while maintaining most free-living prokaryotes and exposed to sunlight (LF, standing for light + filtration), a filtered and diluted treatment $(0.8 \mu \mathrm{m}$ filtered seawater diluted (1:5) with $0.2 \mu \mathrm{m}$ filtered seawater) to reduce both predators and resource competition and exposed to sunlight (LFD, standing for light + filtration + dilution) and a filtered and diluted treatment kept under dark conditions (DFD, standing for dark + filtration + dilution). A control, consisting of unmanipulated seawater exposed to sunlight (LC, standing for light control) was also incubated in order to check for changes in bacterial community composition associated with sample manipulation. LC, LF and LFD samples were incubated on deck under natural light conditions while the DFD treatment was also incubated on deck under dark conditions, by carefully covering the carboys with two layers of black tape. The 
experimental carboys were kept at near in situ temperature $\left( \pm 1^{\circ} \mathrm{C}\right)$ by circulating surface seawater through the incubation tank. The incubations lasted 3 days and samples were taken every 12-24 h for heterotrophic prokaryotic biomass (HPB) (as estimated by flow cytometry) and leucine incorporation rate measurements. Empirically derived leucine-tocarbon conversion factors were used to estimate heterotrophic prokaryotic production (HPP) (Teira et al., 2015). Growth rates (GR) at the community level were calculated at each time point simply by dividing HPP by HPB (Kirchman, 2016). DNA samples for prokaryotic community composition analyses were taken from all treatments at the end of the incubations.

\section{Flow cytometry analyses}

Samples were fixed and processed with a FACSCalibur flow cytometer (BD-Biosciences) with a blue laser emitting at $488 \mathrm{~nm}$. Samples of $1.2 \mathrm{~mL}$ seawater were fixed with a paraformaldehyde-glutaraldehyde mix ( $1 \%$ and $0.05 \%$ final concentrations, respectively) and stored at $-80^{\circ} \mathrm{C}$ until analysis in the laboratory within a maximum of seven months after the end of the cruise. Samples were stained with SYBRGreen I, at a final concentration of 1:10.000, for $15 \mathrm{~min}$ in the dark at room temperature. The average flow rate used was 12 $\mu \mathrm{L} \min ^{-1}$ and acquisition time ranged from 30 to 260 seconds depending on cell concentration in each sample. Data were inspected in a green fluorescence (FL1) versus light side scatter (SSC) plot and analyzed as detailed as in Gomes et al. (2015). Molecular Probes latex beads $(1 \mu \mathrm{m})$ were always used as internal standards. The biovolume of 
prokaryotic cells was estimated using the calibration obtained by Calvo-Díaz and Morán (2006) relating relative light side scatter (population SSC divided by bead SSC) to cell diameter assuming spherical shape. Cell biovolume was finally converted into carbon biomass with the Gundersen et al. (2002) equation: cell biomass $\left(\mathrm{fg} \mathrm{C}\right.$ cell $\left.^{-1}\right)=108.8 *$ V0.898.

\section{Leucine incorporation rates}

The $\left[{ }^{3} \mathrm{H}\right]$ leucine incorporation method (Kirchman et al., 1985), modified as described by Smith and Azam (1992), was used to determine leucine incorporation rates. From each experimental carboy, six $1.5 \mathrm{~mL}$ vials (4 replicates and 2 killed controls) were filled with $1.2 \mathrm{~mL}$ of seawater. A total of $120 \mu \mathrm{L}$ of cold $50 \%$ trichloroacetic acid (TCA) was added to the killed controls. After 15 minutes, $20 \mathrm{nmol} \mathrm{L}^{-1}$ of L-[4,5- $\left.{ }^{3} \mathrm{H}\right]$ leucine $\left(144.2 \mathrm{Ci} \mathrm{mmol}^{-1}\right.$, Amersham) was added to all samples, which were incubated for 2.5-6 $\mathrm{h}$ in the same incubation tank and under the same light conditions as the corresponding experimental carboys. Incubations were terminated by adding TCA (5\% final concentration) to the samples. The prokaryotic cells were pelleted by two successive centrifugation steps (12000 rpm, $10 \mathrm{~min}$ ), including a washing step with $1 \mathrm{~mL}$ of $5 \%$ TCA following Kirchman et al. (1985) with slight modifications (Smith and Azam, 1992). Scintillation cocktail was added to the pellets and after $18 \mathrm{~h}$, the radioactivity was determined in a liquid scintillation counter (Wallac-PerkinElmer).

High-Throughput sequencing 
In order to characterize the initial prokaryotic community at each sampling site (sample from station 7 was lost) 6-12 L of surface seawater (3 m depth) was sequentially filtered through a $200-\mu \mathrm{m}$ and a $20-\mu \mathrm{m}$ mesh to remove large plankton. Further filtering was done by serially pumping water through $47-\mathrm{mm}$ polycarbonate (Nucleopore Whatmann) membrane filters of $3 \mu \mathrm{m}$ and $0.2 \mu \mathrm{m}$ pore size with a peristaltic pump (Masterflex, EW77410-10). The filters were then flash-frozen in liquid $\mathrm{N}_{2}$ and stored at $-80^{\circ} \mathrm{C}$ until DNA extraction. The time span from bottle closing to filter freezing was $\sim 4 \mathrm{~h}$ and, except for the time needed to empty the rosette bottles, the water was kept at $4^{\circ} \mathrm{C}$. DNA extractions from the $0.2 \mu \mathrm{m}$ filter were performed using the standard phenol-chloroform protocol (Massana et al. 1997). At the end of each experiment, water from treatment duplicates was pooled and 1-2 L was filtered through a $0.2 \mu \mathrm{m}$ pore-size polycarbonate filters (Nuclepore Whatmann, 47-mm filter diameter). Filters were then stored at $-80^{\circ} \mathrm{C}$ until DNA extraction. Microbial community DNA was extracted from the $0.2 \mu \mathrm{m}$ filter using the Ultra Clean Soil DNA isolation kit (MoBio Laboratories, Inc.) and quantified in a Nanodrop. Samples from the end of experiments 6 and 7 were not available for sequencing. The different extraction protocols for the field samples and the experimental samples precluded us to make statistical comparisons between both sets of samples. Nevertheless, we include data from field samples to provide information about the initial prokaryotic communities.

Prokaryotic diversity was assessed in the $0.2-3 \mu \mathrm{m}$ fraction of initial and experiment samples by amplicon sequencing of the hypervariable V4-V5 ( 400 bp) region of the 16S 
rRNA gene with the Illumina MiSeq platform (iTags) using paired-end reads $(2 \times 250 \mathrm{bp})$ and primers 515F-Y - 926R targeting both Archaea and Bacteria (Parada et al., 2016). Amplicon libraries were sequenced at the Research and Testing Laboratory facility (Lubbock, TX, USA; rtlgenomics.com/). Reads were processed following an in-house pipeline (Logares, 2017). Briefly, raw reads were corrected using BayesHammer (Nikolenko et al., 2013) following Schirmer et al. (2015). Corrected paired-end reads were subsequently merged with PEAR (Zhang et al., 2014) and sequences $>200$ bp were qualitychecked and de-replicated using USEARCH (Edgar 2010). Operational Taxonomic Units (OTUs) were delineated at 97\% similarity using UPARSE V8 (Edgar 2013). To obtain OTU abundances, reads were mapped back to OTUs at 97\% similarity. Chimera check and removal was performed both de novo and using the SILVA reference database (Quast et al., 2013). Taxonomic assignment was generated by BLASTing (Altschul, et al. 1990) OTU representative sequences against the SILVA database. In order to compare both alpha and beta diversity among experimental treatments, the raw OTU table was subsampled using "rrarefy" (Vegan package in R) to the number of reads present in the sample with the lowest amount of reads, which was 7,747. Sequences are publicly available at the European Nucleotide Archive (http://www.ebi.ac.uk/ena) under the accession numbers PRJEB25570 (sequences from experiments) and PRJEB25224 (sequences from field samples).

Statistical analyses 
To compare the impact of experimental manipulations on growth, we first calculated the response ratios at each sampling time as the quotient between the mean growth rates (from duplicates)of two different treatments. The relative error of each quotient was estimated as the square root of the sum of the squares of the relative errors in the individual variables. To account for the diverse time-courses observed in growth rates (Fig. S1), we calculated the time-averaged response ratios for each experiment. The effect of grazing reduction (i.e. effect of filtration) was estimated by dividing a given response variable in LF by that in LC (LF/LC), the effect of resource competition reduction (i.e. effect of dilution) by dividing a given response variable in LF by that in LFD (LF/LFD) and the effect of light by dividing a given response variable in LFD by that in DFD (LFD/DFD). The non-parametric Wilcoxon test (two-tailed) was applied to compare time-averaged response ratios derived for each experiment against a constant value of one in order to detect significant responses to the different treatments. The Z-test was used to compare the mean response ratios (pooling the data from all experiments) against a constant value of one in order to detect significant responses to the different treatments. The p-value was standardized as proposed by Good (1982) in order to overcome the low number of samples.

The sequence abundances of the subsampled OTU table were transformed using the centered log ratio (clr) (Fernandes et al., 2014; Gloor et al., 2017) using the web-based program Calypso 8.72 . Zeros were replaced by the minimum value that is larger than 0 divided by 2 . Variance partitioning by redundancy analysis (RDA) filtering for the top 100 
most abundant OTUs was used to analyze community composition variation against sampling site and experimental treatment. Permutation tests of the factors included in Redundancy Analysis (RDA) (experiment and treatment) were conducted to test for significance. The DeSeq2 procedure (Love et al 2014), based on negative binomial generalized linear model, was used to detect differentially abundant OTUs between experimental treatments using the web-based program Calypso 8.62. The input for DeSeq2 was the raw (not subsampled) data set. As recommended for this method we removed rare OTUs from the data set (i.e. those OTUs contributing $<0.01 \%$ of the total sequence abundance). Benjamini-Hochberg-Yekutieli procedure was used to control false discovery rate (FDR) (Benjamini and Yekutieli 2001).

Acknowledgments: This study was supported by the by the Spanish Ministerio de Ciencia e Innovación through project Consolider-Ingenio Malaspina 2010 (CSD2008-00077). Sample sequencing was funded by grant M'OMICS-MALAN (CTM2011-15461-E PI) of the Spanish Ministerio de Economía y Competitividad. We thank our fellow scientists, chief scientists, and the crew of BIO Hespérides for their work, Carlos M. Duarte for the conception and coordination of the Malaspina 2010 Circumnavigation Expedition, the members of the physical oceanography party for collecting, calibrating, and processing the CTD data, the providers of chlorophyll $a$ (Marta Estrada) and nutrient data (Dolors Blasco and Montse Vidal), and the people involved in the experimental set-up (Hugo Sarmento, 
Ana Gomes, Francisco M. Cornejo-Castillo, Laura Alonso-Sáez, Victor Hernando, Irene

Forn, Joaquín Valencia and Teresa Serrano).

\section{References}

Allers, E., Gómez-Consarnau, L., Pinhassi, J., Simek, K., Gasol, J. M., and Pernthaler, J. (2007) Population dynamics of Alteromonas and Roseobacter in marine mesocosms after substrate and nutrient manipulations. Environ Microbiol 9: 2417-2429.

Alonso-Sáez, L., Gasol, J. M., Lefort, T., Hofer, J., and Sommaruga, R. (2006) Effect of natural sunlight on bacterial activity and differential sensitivity of natural bacterioplankton groups in northwestern Mediterranean coastal waters. Appl and Environ Microbiol 72: 5806-5813.

Alonso-Sáez, L., Díaz-Pérez, L., and Morán, X.A.G. (2015) The hidden seasonality of the rare biosphere in coastal marine bacterioplankton. Environ Microbiol 17: 3766-3780.

Altschul, S.F., Gish, W., Miller, W., Myers, E.W., and Lipman, D.J. (1990) Basic local alignment search tool. $J$ Mol Biol 215:403-410.

Aylward, F. O., McDonald, B. R., Adams, S. M., Valenzuela, A., Schmidt, R. A., Goodwin, L. A., ... and Poulsen, M. (2013). Comparison of 26 sphingomonad genomes reveals diverse environmental adaptations and biodegradative capabilities. Applied and environmental Microbiology 79: 3724-3733.

Baltar, F., Palovaara, J., Unrein, F., Catala, P., Horňák, K., Šimek, K., et al. (2016) Marine bacterial community structure resilience to changes in protist predation under phytoplankton bloom conditions. ISME J 10: 568-581.

Béjà, O., Spudich, E. N., Spudich, J.L., Leclerc, M., and DeLong, E.F. (2001) Proteorhodopsin phototrophy in the ocean. Nature 411: 786-789.

Benjamini, Y., and Yekutieli, D. (2001). The control of the false discovery rate in multiple testing under dependency. Annals of statistics: 1165-1188.

Bertoni, R., Jeffrey, W.H., Pujo-Pay, M., Oriol, L., Conan, P., and Joux, F. (2011) Influence of water mixing on the inhibitory effect of UV radiation on primary and bacterial production in Mediterranean coastal water. Aquat Sci 73: 377-387. 
Biller, S.J., Berube, P.M., Lindell, D., and Chisholm, S.W. (2015) Prochlorococcus: the structure and function of collective diversity. Nature Rev Microbiol 13: 13-27.

Brinkhoff, T., Giebel, H. A., and Simon, M. (2008). Diversity, ecology, and genomics of the Roseobacter clade: a short overview. Archives of microbiology 189(6): 531-539.

Buchan, A., González, J. M., and Moran, M. A. (2005). Overview of the marine Roseobacter lineage. Applied and environmental microbiology 71(10): 5665-5677.

Cabello, A. M., Cornejo-Castillo, F. M., Raho, N., Blasco, D., Vidal, M., Audic, ...and Massana, R. (2016). Global distribution and vertical patterns of a prymnesiophytecyanobacteria obligate symbiosis. The ISME journal 10(3): 693.

Calvo-Díaz, A., Díaz-Pérez, L., Suárez, L.Á., Morán, X.A.G., Teira, E., and Marañón, E. (2011) Decrease in the autotrophic-to-heterotrophic biomass ratio of picoplankton in oligotrophic marine waters due to bottle enclosure. Appl and Environ Microbiol 77: 5739-5746.

Carlson, C.A., and Ducklow, H.W. (1996) Growth of bacterioplankton and consumption of dissolved organic carbon in the Sargasso Sea. Aquat Microb Ecol, 10(1), 69-85.

Caron, D.A., Lim, E.L., Sanders, R.W., Dennett, M.R., and Berninger, U.G. (2000) Responses of bacterioplankton and phytoplankton to organic carbon and inorganic nutrient addition in two oceanic ecosystems. Aquat Microb Ecol 22: 175-184.

Clarke, K.R., and Gorley, R.N. (2006) Primer. Primer-E, Plymouth.

Corno, G., and Jürgens, K. (2008) Structural and functional patterns of bacterial communities in response to protist predation along an experimental productivity gradient. Environ Microbiol 10: 2857-2871.

Cottrell, M.T., and Kirchman, D.L. (2016) Transcriptional control in marine copiotrophic and oligotrophic bacteria with streamlined genomes. Appl Environ Microbiol 82:60106018 .

Cram, J.A., Parada, A.E., and Fuhrman, J.A. (2016) Dilution reveals how viral lysis and grazing shape microbial communities. Limnol Oceanogr 61: 889-905.

Dadon-Pilosof, A., Conley, K.R., Jacobi, Y., Haber, M., Lombard, F., Sutherland, K., et al. (2017) Surface properties of SAR11 bacteria facilitate grazing avoidance. Nature Microbiol 2:1608-1615. 
Edgar, R.C. (2010) Search and clustering orders of magnitude faster than BLAST. Bioinformatics 26: 2460-2461.

Edgar RC. (2013) UPARSE: highly accurate OTU sequences from microbial amplicon reads. Nat Methods 10: 996-998.

Estrada, M., Delgado, M., Blasco, D., Latasa, M., Cabello, A. M., Benítez-Barrios, V., ... and Vidal, M. (2016). Phytoplankton across tropical and subtropical regions of the Atlantic, Indian and Pacific oceans. PLoS One 11(3): e0151699.

Fernandes, A. D., Reid, J. N., Macklaim, J. M., McMurrough, T. A., Edgell, D. R., and Gloor, G. B. (2014). Unifying the analysis of high-throughput sequencing datasets: characterizing RNA-seq, 16S rRNA gene sequencing and selective growth experiments by compositional data analysis. Microbiome 2(1): 15 .

Fernández-Castro, B., Mouriño-Carballido, B., Benítez-Barrios, V.M., Chouciño, P., FraileNuez, E., Graña, R., et al. (2014) Microstructure turbulence and diffusivity parameterization in the tropical and subtropical Atlantic, Pacific and Indian Oceans during the Malaspina 2010 expedition. Deep Sea Res I 94: 15-30.

Ferrera, I., Gasol, J. M., Sebastián, M., Hojerová, E., and Koblížek, M. (2011) Comparison of growth rates of aerobic anoxygenic phototrophic bacteria and other bacterioplankton groups in coastal Mediterranean waters. Appl Environ Microbiol 77: 7451-7458.

Ferrera, I., Sánchez, O., Kolářová, E., Koblížek, M., and Gasol, J.M. (2017) Light enhances the growth rates of natural populations of aerobic anoxygenic phototrophic bacteria. ISME J 11: 2391-2393.

Fuchs, B. M., Zubkov, M. V., Sahm, K., Burkill, P. H., and Amann, R. (2000). Changes in community composition during dilution cultures of marine bacterioplankton as assessed by flow cytometric and molecular biological techniques. Environmental Microbiology 2(2): 191-201.

Fuhrman, J.A., and Noble, R.T. (1995) Viruses and protists cause similar bacterial mortality in coastal seawater. Limnol Oceanogr 40: 1236-1242.

Galí, M., Simó, R., Pérez, G., Ruiz-González, C., Sarmento, H., Royer, S.J., et al. (2013) Differential response of planktonic primary, bacterial, and dimethylsulfide production rates to static vs. dynamic light exposure in upper mixed-layer summer sea waters. Biogeosciences 10: 7983-7998. 
Gasol, J. M., and Moran, X. A. (1999). Effects of filtration on bacterial activity and picoplankton community structure as assessed by flow cytometry. Aquatic microbial ecology 16(3): 251-264.

Gasol, J.M., and del Giorgio, P.A. (2000) Using flow cytometry for counting natural planktonic bacteria and understanding the structure of planktonic bacterial communities. Sci Mar 64: 197-224.

Gasol, J.M., Pedrós-Alió, C., and Vaqué, D. (2002) Regulation of bacterial assemblages in oligotrophic plankton systems: results from experimental and empirical approaches. Antonie Van Leeuwenhoek 81: 435-452.

Gifford, S.M., Sharma, S., Booth, M., and Moran, M.A. (2013) Expression patterns reveal niche diversification in a marine microbial assemblage. ISME J 7: 281-298.

Giovannoni, S.J. (2017) SAR11 bacteria: the most abundant plankton in the oceans. Annu Rev Mar Sci 9: 231-255.

Gloor, G. B., Macklaim, J. M., Pawlowsky-Glahn, V., and Egozcue, J. J. (2017). Microbiome datasets are compositional: and this is not optional. Frontiers in microbiology 8: 2224.

Gomes, A., Gasol, J.M., Estrada, M., Franco-Vidal, L., Díaz-Pérez, L., Ferrera, I., and Morán, X.A.G. (2015) Heterotrophic bacterial responses to the winter-spring phytoplankton bloom in open waters of the NW Mediterranean. Deep Sea Res I 96: 5968.

Gómez-Consarnau, L., González, J.M., Coll-Lladó, M., Gourdon, P., Pascher, T., Neutze, R., et al. (2007) Light stimulates growth of proteorhodopsin-containing marine Flavobacteria. Nature 445: 210-213.

Good, I.J. (1982) C140. Standardized tail-area probabilities. Journal of Statistical Computation and Simulation 16: 65-66.

Gundersen, K., Heldal, M., Norland, S., Purdie, D.A., and Knap, A.H. (2002) Elemental C, $\mathrm{N}$, and $\mathrm{P}$ cell content of individual bacteria collected at the Bermuda Atlantic Time series Study (BATS) site. Limnol Oceanogr 47: 1525-1530.

Hale, M.S., Li, W.K., and Rivkin, R.B. (2017) Meridional patterns of inorganic nutrient limitation and co-limitation of bacterial growth in the Atlantic Ocean. Prog Oceanogr 158: $90-98$. 
Hogle, S. L., Bundy, R. M., Blanton, J. M., Allen, E. E., and Barbeau, K. A. (2016). Copiotrophic marine bacteria are associated with strong iron-binding ligand production during phytoplankton blooms. Limnology and Oceanography Letters 1(1): 36-43.

Hütz, A., Schubert, K., and Overmann, J. (2011). Thalassospira sp. isolated from the oligotrophic eastern Mediterranean Sea exhibits chemotaxis toward inorganic phosphate during starvation. Applied and environmental microbiology 77: 4412-4421.

Jürgens, K., and Matz, C. (2002) Predation as a shaping force for the phenotypic and genotypic composition of planktonic bacteria. Antonie van Leeuwenhoek 81: 413-434.

Kataoka, T., Hodoki, Y., Suzuki, K., Saito, H., and Higashi, S. (2009) Detection of UVBRsensitive and-tolerant bacteria in surface waters of the western North Pacific. Journal of Photochemistry and Photobiology B: Biology, 95(2), 108-116.

Kirchman, D., K'nees, E., and Hodson, R. (1985) Leucine incorporation and its potential as a measure of protein synthesis by bacteria in natural aquatic systems. Appl Environ Microbiol 49: 599-607.

Kirchman, D.L. (2016) Growth rates of microbes in the oceans. Annu Rev Mar Sci 8: 285309.

Kolber, Z.S., Van Dover, C.L., Niederman, R.A., and Falkowski, P.G. (2000) Bacterial photosynthesis in surface waters of the open ocean. Nature, 407(6801), 177-179.

Korlević, M., Ristova, P.P., Garić, R., Amann, R., and Orlić, S. (2015) Bacterial diversity in the South Adriatic Sea during a strong, deep winter convection year. Appl Environ Microbiol 81: 1715-1726.

Langenheder, S., Sobek, S., and Tranvik, L.J. (2006) Changes in bacterial community composition along a solar radiation gradient in humic waters. Aquat Sci 68: 415-424.

Larsen, A., Flaten, G.A.F., Sandaa, R.A., Castberg, T., Thyrhaug, R., Erga, S.R., et al. (2004) Spring phytoplankton bloom dynamics in Norwegian coastal waters: microbial community succession and diversity. Limnol Oceanogr 49: 180-190.

Lauro, F. M., McDougald, D., Thomas, T., Williams, T.J., Egan, S., Rice, S., et al. (2009) The genomic basis of trophic strategy in marine bacteria. Proc Natl Acad Sci USA 106: 15527-15533.

Logares R. 2017. Workflow for Analysing MiSeq Amplicons based on Uparse v1.5. In: https://doi.org/10.5281/zenodo.259579. 
Longhurst, A.R. (2010) Ecological geography of the sea. Elsevier.

Love, M. I., Huber, W., and Anders, S. (2014). Moderated estimation of fold change and dispersion for RNA-seq data with DESeq2. Genome biology 15(12): 550.

Manrique, J.M., Calvo, A. Y., Halac, S.R., Villafañe, V.E., Jones, L.R., and Helbling, E. W. (2012) Effects of UV radiation on the taxonomic composition of natural bacterioplankton communities from Bahía Engaño (Patagonia, Argentina) J Photochem Photobiol B: Biol 117: 171-178.

Martínez-García, S., Fernández, E., Calvo-Díaz, A., Marañón, E., Morán, X.A.G., and Teira, E. (2010) Response of heterotrophic and autotrophic microbial plankton to inorganic and organic inputs along a latitudinal transect in the Atlantic Ocean. Biogeosciences 7: 1701-1713.

Massana, R., Murray, A.E., Preston, C.M., and DeLong, E.F. (1997) Vertical distribution and phylogenetic characterization of marine planktonic Archaea in the Santa Barbara Channel. Appl Environ Microbiol 63:50-56.

Matallana-Surget, S., Villette, C., Intertaglia, L., Joux, F., Bourrain, M., and Lebaron, P. (2012) Response to UVB radiation and oxidative stress of marine bacteria isolated from South Pacific Ocean and Mediterranean Sea. J Photochem Photobiol B: Biol 117: 254261.

Moran, M. A., Belas, R., Schell, M. A., Gonzalez, J. M., Sun, F., Sun, S., ... and Howard, E. C. (2007). Ecological genomics of marine Roseobacters. Applied and environmental microbiology 73(14):4559-4569.

Morán, X. A. G., Massana, R., and Gasol, J. M. (2001). Light conditions affect the measurement of oceanic bacterial production via leucine uptake. Applied and environmental microbiology 67(9): 3795-3801.

Morán, X.A.G., Gasol, J.M., Pernice, M.C., Mangot, J.F., Massana, R., Lara, E., et al. (2017) Temperature regulation of marine heterotrophic prokaryotes increases latitudinally as a breach between bottom

Glpbarchtonge dibioln controls. 23: 3956-3964.

Morris, R.M., Rappé, M.S., Connon, S.A., Vergin, K.L., Siebold, W.A., Carlson, C. A., and Giovannoni, S.J. (2002) SAR11 clade dominates ocean surface bacterioplankton communities. Nature 420: 806-810. 
Muñoz-Marín, M.C., Luque, I., Zubkov, M.V., Hill, P.G., Diez, J., and García-Fernández, J.M. (2013) Prochlorococcus can use the Pro1404 transporter to take up glucose at nanomolar concentrations in the Atlantic Ocean. Proc Natl Acad Sci USA 110: 85978602 .

Neale, P.J., Helbling, E.W., and Zagarese, H.E. (2003) Modulation of UVR exposure and effects by vertical mixing and advection. In: Helbling, E.W., and Zagarese, H. (eds.) UV effects in aquatic organisms and ecosystems. The Royal Society of Chemistry, Cambridge, pp. 107-134.

Nikolenko, S.I., Korobeynikov, A.I., Alekseyev, M.A. (2013) BayesHammer: Bayesian clustering for error correction in single-cell sequencing. BMC Genomics 14: Suppl 1:S7.

Oksanen, J., Blanchet, F. G., Kindt, R., Legendre, P., Minchin, P. R., O'hara, R. B., et al. (2015) Vegan: Community Ecology Package. R package version 2.0-10. 2013.

Overmann, J., and Lepleux, C. (2016) Marine Bacteria and Archaea: Diversity, Adaptations, and Culturability. In: Stal, L., and Cretoiu, M.S. (eds) The Marine Microbiome. Springer International Publishing, The Netherlands, pp. 21-55.

Parada, A.E., Needham, D.M., and Fuhrman, J.A. (2016) Every base matters: assessing small subunit rRNA primers for marine microbiomes with mock communities, time series and global field samples. Environ Microbiol 18: 1403-1414.

Partensky, F., Hess, W.R., and Vaulot, D. (1999) Prochlorococcus, a marine photosynthetic prokaryote of global significance. Microbiol Mol Biol Rev 63: 106-127.

Pernthaler, J., Posch, T., Šimek, K., Vrba, J., Pernthaler, A., Glöckner, F.O., et al. (2001) Predator-specific enrichment of actinobacteria from a cosmopolitan freshwater clade in mixed continuous culture. Appl Environ Microbiol 67: 2145-2155.

Pernthaler, J. (2005) Predation on prokaryotes in the water column and its ecological implications. Nature Rev Microbiol 3: 537-546.

Pinhassi, J., DeLong, E.F., Béjà, O., González, J.M., and Pedrós-Alió, C. (2016) Marine bacterial and archaeal ion-pumping rhodopsins: genetic diversity, physiology, and ecology. Microbiol Mol Biol Rev 80: 929-954.

Piquet, A.M.T., Bolhuis, H., Davidson, A.T., and Buma, A.G. (2010) Seasonal succession and UV sensitivity of marine bacterioplankton at an Antarctic coastal site. FEMS Microbiol Ecol 73: 68-82. 
Quast, C., Pruesse, E., Yilmaz, P., Gerken, J., Schweer, T., Yarza, P., Peplies, J., and Glockner, F.O. (2013) The SILVA ribosomal RNA gene database project: improved data processing and web-based tools. Nucleic Acids Res 41: D590-596.

Ram, A.P., Chaibi-Slouma, S., Keshri, J., Colombet, J., and Sime-Ngando, T. (2016) Functional Responses of Bacterioplankton Diversity and Metabolism to Experimental Bottom-Up and Top-Down Forcings. Microb Ecol 72: 347-358.

Richert, I., Dinasquet, J., Logares, R., Riemann, L., Yager, P.L., Wendeberg, A., and Bertilsson, S. (2015) The influence of light and water mass on bacterial population dynamics in the Amundsen Sea Polynya. Elem Sci Anth 3: 000044.

Ruiz-González, C., Lefort, T., Galí, M., Sala, M.M., Sommaruga, R., Simó, R., and Gasol, J.M. (2012) Seasonal patterns in the sunlight sensitivity of bacterioplankton from Mediterranean surface coastal waters. FEMS Microbiol Ecol 79: 661-674.

Ruiz-González, C., Simó, R., Sommaruga, R., and Gasol, J.M. (2013) Away from darkness: a review on the effects of solar radiation on heterotrophic bacterioplankton activity. Front Microbiol 4: 131.

Sánchez, O., Koblížek, M., Gasol, J.M., and Ferrera, I. (2017) Effects of grazing, phosphorus and light on the growth rates of major bacterioplankton taxa in the coastal NW Mediterranean. Environ Microbiol Reports 9: 300-309.

Sanders, R.W., Caron, D.A., and Berninger, U.G. (1992) Relationships between bacteria and heterotrophic nanoplankton in marine and fresh waters: an inter-ecosystem comparison. Mar Ecol Progr Ser 86: 1-14.

Santos, A.L., Lopes, S., Baptista, I., Henriques, I., Gomes, N.C.M., Almeida, A., et al. (2011) Diversity in UV sensitivity and recovery potential among bacterioneuston and bacterioplankton isolates. Lett Appl Microbiol 52: 360-366.

Scanlan, D. J., Ostrowski, M., Mazard, S., Dufresne, A., Garczarek, L., Hess, W. R. et al. (2009) Ecological genomics of marine picocyanobacteria. Microbiol Mol Biol Rev, 73: 249-299.

Schirmer, M., Ijaz, U.Z., D'Amore, R., Hall, N., Sloan, W.T., and Quince, C. (2015) Insight into biases and sequencing errors for amplicon sequencing with the Illumina MiSeq platform. Nucleic Acids Res 43: e37.

Schwalbach, M.S., Brown, M., and Fuhrman, J.A. (2005) Impact of light on marine bacterioplankton community structure. Aquat Microb Ecol 39: 235-245. 
Silva, L., Calleja, M. L., Huete-Stauffer, T. M., Ivetic, S., Ansari, M. I., Viegas, M., and Morán, X. A. G. (2019). Low abundances but high growth rates of coastal heterotrophic bacteria in the Red Sea. Frontiers in Microbiology 9: 3244.

Šimek, K., Pernthaler, J., Weinbauer, M.G., Hornák, K., Dolan, J. R., Nedoma, J., et al. (2001) Changes in bacterial community composition and dynamics and viral mortality rates associated with enhanced flagellate grazing in a mesoeutrophic reservoir. Appl Environ Microbiol 67: 2723-2733.

Smith, D.C., and Azam, F. (1992) A simple, economical method for measuring bacterial protein synthesis rates in seawater using 3H-leucine. Mar Microb Food Webs 6: 107114.

Storesund, J.E., Erga, S.R., Ray, J.L., Thingstad, T.F., and Sandaa, R.A. (2015) Top-down and bottom-up control on bacterial diversity in a western Norwegian deep-silled fjord. FEMS Microbiol Ecol 91: fiv076.

Straza, T.R., and Kirchman, D.L. (2011) Single-cell response of bacterial groups to light and other environmental factors in the Delaware Bay, USA. Aquat Microb Ecol 62: 267277.

Strom, S.L. (2000) Bacterivory: interactions between bacteria and their grazers. In: Kirchman, D.L. (ed) Microbial ecology of the oceans. Wiley-Liss, New York, pp 351385.

Strom, S.L. (2008) Microbial ecology of ocean biogeochemistry: a community perspective. Science 320:1043-1045.

Sunagawa, S., Coelho, L.P., Chaffron, S., Kultima, J.R., Labadie, K., Salazar, G., et al. (2015) Structure and function of the global ocean microbiome. Science, 348(6237), 1261359.

Tedetti, M., and Sempéré, R. (2006) Penetration of ultraviolet radiation in the marine environment. A review. Photochem Photobiol 82: 389-397.

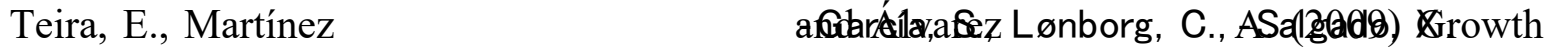
rates of different phylogenetic bacterioplankton groups in a coastal upwelling system. Environ Microbiol Reports 1: 545-554.

Teira, E., Martínez-García, S., Calvo-Díaz, A., and Morán, X.A.G. (2010) Effects of inorganic and organic nutrient inputs on bacterioplankton community composition along a latitudinal transect in the Atlantic Ocean. Aquat Microb Ecol 60:299-313. 
Teira, E., Martínez-García, S., Carreira, C., and Morán, X.A.G. (2011) Changes in bacterioplankton and phytoplankton community composition in response to nutrient additions in coastal waters off the NW Iberian Peninsula. Mar Ecol Progr Ser 426:87104.

Teira, E., Hernando-Morales, V., Cornejo-Castillo, F.M., Alonso-Sáez, L., Sarmento, H., Valencia-Vila, J., et al. (2015) Sample dilution and bacterial community composition influence empirical leucine-to-carbon conversion factors in surface waters of the world's oceans. Appl Environ Microbiol 81: 8224-8232.

Thingstad, T.F., and Lignell, R. (1997) Theoretical models for the control of bacterial growth rate, abundance, diversity and carbon demand. Aquat Microb Ecol 13: 19-27.

Thingstad, T.F. (2000) Elements of a theory for the mechanisms controlling abundance, diversity, and biogeochemical role of lytic bacterial viruses in aquatic systems. Limnol Oceanogr 45: 1320-1328.

van Dorst, J., Bissett, A., Palmer, A. S., Brown, M., Snape, I., Stark, J.S., et al. (2014) Community fingerprinting in a sequencing world. FEMS Microbiol Ecol 89: 316-330.

Wagner-Döbler, I., and Biebl, H. (2006). Environmental biology of the marine Roseobacter lineage. Annu Rev Microbiol 60: 255-280.

Wilcox, R.M., and Fuhrman, J.A. (1994) Bacterial viruses in coastal seawater: lytic rather than lysogenic production. Mar Ecol Progr Ser 114: 35-45.

Winter, C., Moeseneder, M.M., and Herndl, G.J. (2001) Impact of UV radiation on bacterioplankton community composition. Appl Environ Microbiol 67: 665-672.

Zhang, R., Weinbauer, M.G., and Qian, P.Y. (2007) Viruses and flagellates sustain apparent richness and reduce biomass accumulation of bacterioplankton in coastal marine waters. Environ Microbiol 9: 3008-3018.

Zhang, J., Kobert, K., Flouri, T., and Stamatakis. A. (2014) PEAR: a fast and accurate Illumina Paired-End reAd mergeR. Bioinformatics 30: 614-620.

Zheng, Q., Liu, Y., Steindler, L., and Jiao, N. (2015) Pyrosequencing analysis of aerobic anoxygenic phototrophic bacterial community structure in the oligotrophic western Pacific Ocean. FEMS Microbiol Lett 362: fnv034.

Zubkov, M.V., Fuchs, B.M., Tarran, G.A., Burkill, P.H., and Amann, R. (2003) High rate of uptake of organic nitrogen compounds by Prochlorococcus cyanobacteria as a key to their dominance in oligotrophic oceanic waters. Appl Environ Microbiol 69: 1299-1304. 
This article is protected by copyright. All rights reserved. 


\section{Figure Legends}

Figure 1. Map of locations where sampling for experiments was conducted (A), and relative contribution of the major taxonomic groups of prokaryotes to the global community based on number of $16 \mathrm{~S}$ rRNA gene sequences in surface water at the different locations (B).

Figure 2. Time-averaged response to filtration (LF/LC), dilution (LDF/LF) and light exposure (LFD/DFD) of growth rate in each of the 10 experiments. Eq, equatorial, Atl, Atlantic, Ind, Indian, Pac, Pacific. Error bars represent the propagated standard error (SE). Asterisks indicate a significant effect of filtration (mean LF/LC differs from 1), dilution (mean LFD/LF differs from 1), or light exposure (mean LFD/DFD differs from 1) on specific growth rate using the non-parametric Wilcoxon test.

Figure 3. Relationship between the growth rate response to light exposure and the mixed layer depth $(\mathrm{m})$ in the 10 experiments. The black line represent the fitted potential model.

Figure 4. Box plots showing the response to filtration (LF/LC ), dilution (LDF/LF) and light exposure (LFD/DFD) of growth rate (GR), Richness (S), H' Diversity (Shannon index) and J' Evenness (Pielou index) in the experiments (10 for GR, 8 for S; H' and J'). Fifty percent of the data are included within the limit of the boxes and the caps represent 10th and 90th percentiles The thick black line represents the average for all the experiments. Asterisks indicate a significant effect of filtration (LF/LC differs from 1), dilution (LFD/LF differs from 1) or light exposure (LFD/DFD differs from 1) on specific growth rate, richness, Shannon diversity or evenness using Z-tests. 
Figure 5. Relative contribution of major taxonomic groups of bacteria to community structure (in number of sequences) in the light + unmanipulated (LC), light + filtration $(\mathrm{LF})$, light + filtration + dilution (LFD) and dark + filtration +dilution (DFD) treatments at the end of the experiments. Note that data are not available for experiments 6 and 7 .

Figure 6. Redundancy analysis (RDA) biplot, constrained to visualize the variance in OTU abundance, explained by treatment at the end of the experiments. Squares and solid line represent the light + unmanipulated (LC) treatment, inverted triangles and dashed line represent light + filtration (LF) treatment, circles and crossed circles and dotted lines represent light + filtration + dilution $($ LFD) and dark + filtration + dilution (DFD) treatments, respectively. The DFD is highlighted by light grey shadowing.

Figure 7. Fold-change versus mean $( \pm \mathrm{SE})$ abundance in the subsampled data set of the OTUs identified to be significantly different in abundance between (a) light + unmanipulated (LC) and light + filtration (LF) treatments, or (b) light + filtration (LF) and light + filtration + dilution $($ LFD) treatments by DESeq2 $(\mathrm{p}<0.05$, FDR $<0.1)$. A negative fold-change value denotes lower abundance and a positive fold change value denotes higher abundance in LC compared to LF or LF compared to LFD.

Figure S1. Time-course of growth rates for the light + unmanipulated (LC), light + filtration (LF), light + filtration + dilution (LFD) and dark + filtration + dilution (DFD) treatments in each of the 10 experiments. Eq, equatorial, Atl, Atlantic, Ind, Indian, Pac, 
Pacific. Error bars represent the standard deviation (SD) from duplicates. Note that error bars are not visible when smaller than the symbols. 
Table 1. Environmental conditions at the sampling sites. Temperature (Temp), Surface Photosynthetic Active Radiation (SPAR), chlorophyll-a concentration (Chla), phosphate concentration $\left(\mathrm{PO}_{4}^{-}\right)$, heterotrophic prokaryote abundance (HPA), mixed layer depth (MLD), number of OTUs (S). Shannon diversity index (H'), Pielou eveness index (J'). Discrete measurements derive from $3 \mathrm{~m}$ samples. NA. not available. SPAR represents the mean incident light during the three days of incubation.

\begin{tabular}{|c|c|c|c|c|c|c|c|c|c|c|}
\hline \begin{tabular}{|c|} 
EX- \\
cean
\end{tabular} & $\begin{array}{c}\text { Temp } \\
{ }^{\circ} \mathrm{C}\end{array}$ & $\begin{array}{c}\text { SPAR } \\
\mu E \mathrm{~m}^{-2} \mathrm{~s}^{-1}\end{array}$ & $\begin{array}{l}\text { Chla } \\
\mu \mathrm{g} \mathrm{L}^{-1}\end{array}$ & $\begin{array}{c}\mathrm{PO}_{4}^{-} \\
\mu \mathrm{mol} \mathrm{L}^{-1}\end{array}$ & $\begin{array}{c}\mathrm{NO}_{3}^{-} \\
\mu \mathrm{mol} \mathrm{L}^{-1}\end{array}$ & $\begin{array}{c}\text { HPA } \\
\text { cell mL } \mathrm{mL}^{-1}\end{array}$ & $\begin{array}{c}\text { MLD } \\
\text { m }\end{array}$ & $S$ & $\mathbf{H}^{\prime}$ & J' \\
\hline $1 \mathrm{NT}$ Itl & 24.8 & 1636 & 0.18 & NA & 0.509 & 706199 & 8 & 167 & 2.79 & 0.55 \\
\hline 2-Eq-Atl & 27.5 & 1562 & 0.15 & 0.078 & NA & 1601136 & 70 & 176 & 1.99 & 0.38 \\
\hline 3-C-Atl & 22.5 & 1478 & 0.03 & 0.170 & 0.361 & 280620 & 40 & 171 & 2.97 & 0.58 \\
\hline 4-S-In & 25.9 & 866 & 0.09 & 0.033 & 0.262 & 357757 & 44 & 207 & 3.41 & 0.64 \\
\hline 5-S-In & 21.7 & 1222 & 0.07 & 0.019 & 0.191 & 635132 & 26 & 136 & 1.74 & 0.35 \\
\hline 6-S Pac & 24.0 & NA & 0.13 & 0.089 & 0.143 & 507637 & 90 & 263 & 2.78 & 0.50 \\
\hline /-Ec-Pac & 28.3 & 579 & 0.18 & 0.319 & 2.280 & 481133 & 14 & NA & NA & NA \\
\hline 8-N-Pac & 24.0 & 1249 & 0.09 & 0.083 & 0.028 & 924691 & 100 & 198 & 2.11 & 0.40 \\
\hline '-Pac & 28.2 & 293 & 0.21 & 0.229 & 0.377 & 888244 & 14 & 146 & 2.81 & 0.56 \\
\hline IU-IV-Atl & 28.7 & 579 & 0.09 & 0.068 & 0.340 & 932430 & 32 & 225 & 2.86 & 0.53 \\
\hline
\end{tabular}




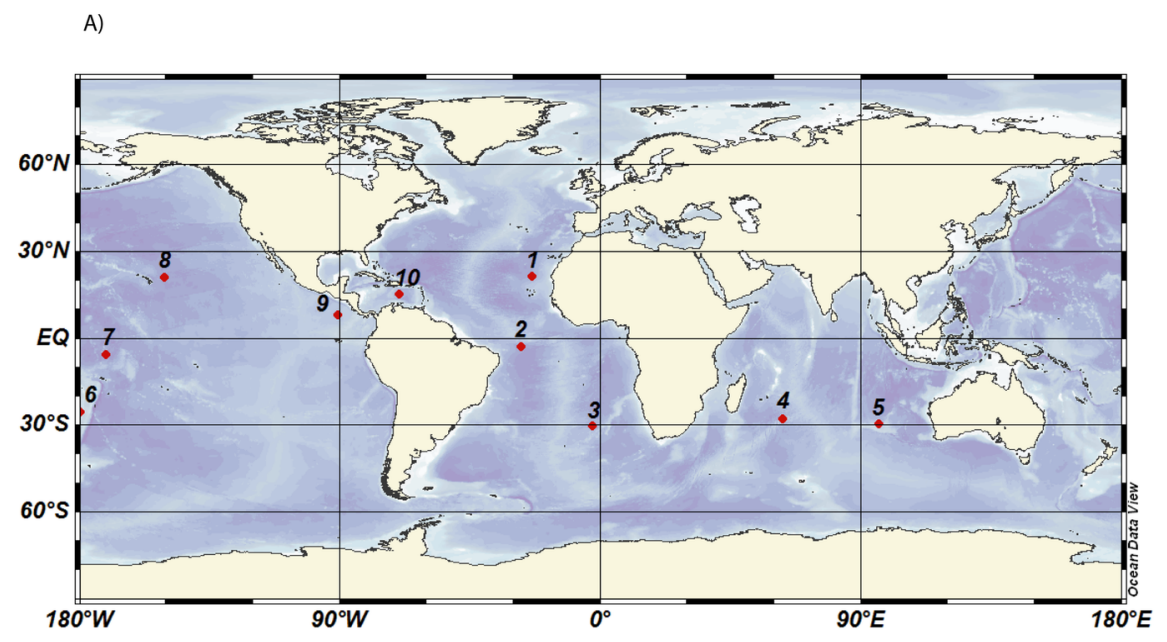

B)

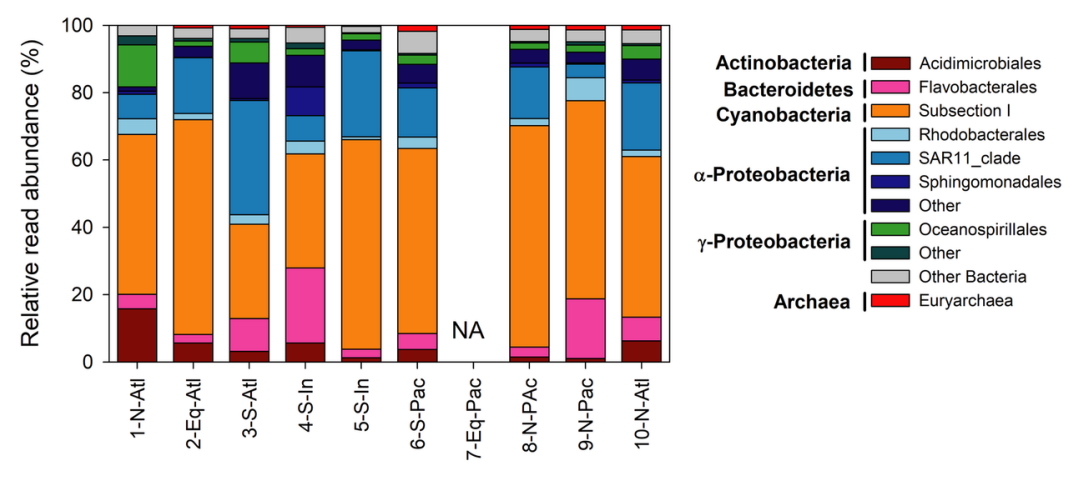

Figure 1 


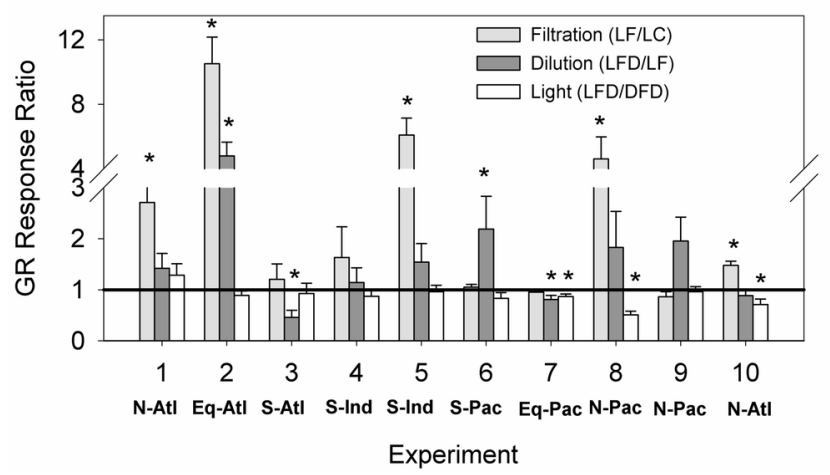

This article is protected by copyright. All rights reserved. 


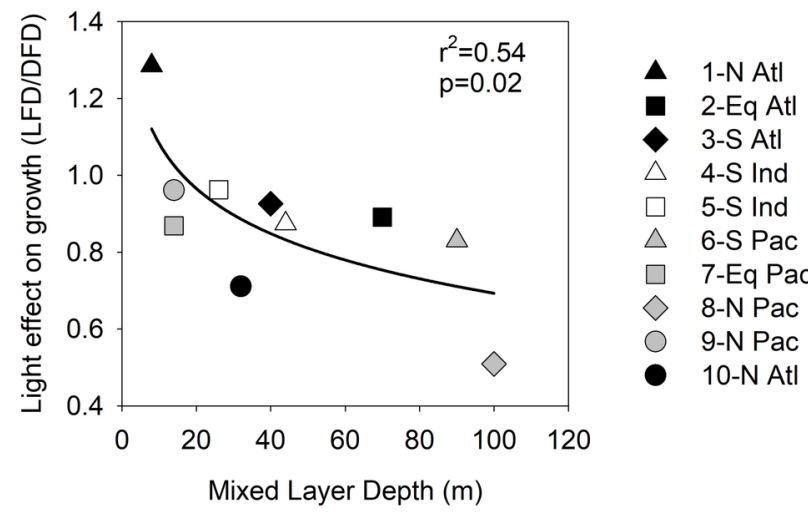

This article is protected by copyright. All rights reserved. 


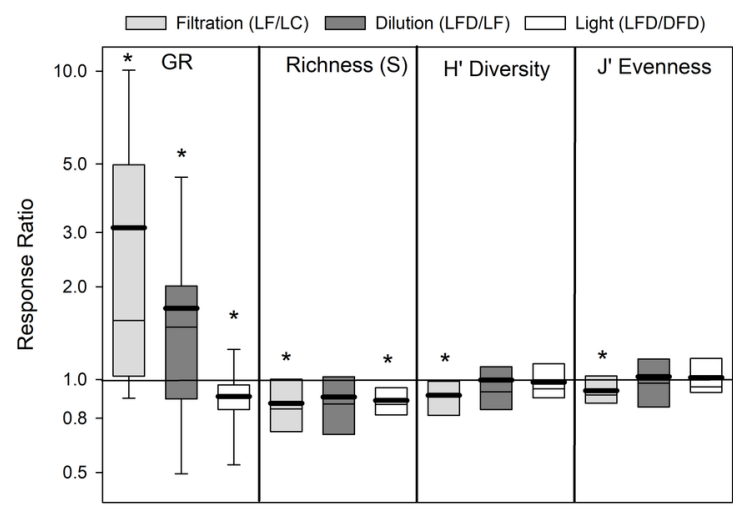

This article is protected by copyright. All rights reserved. 

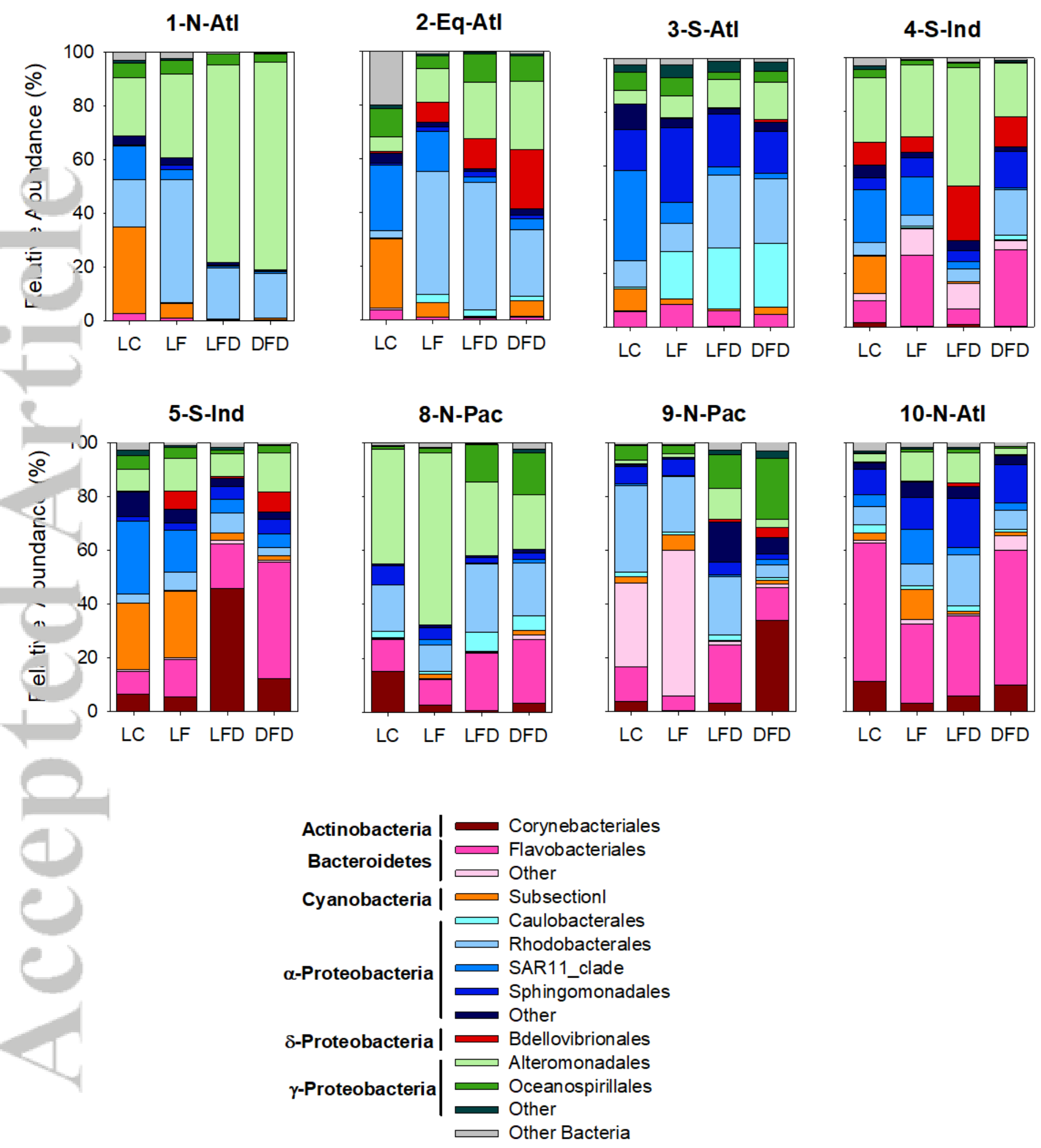


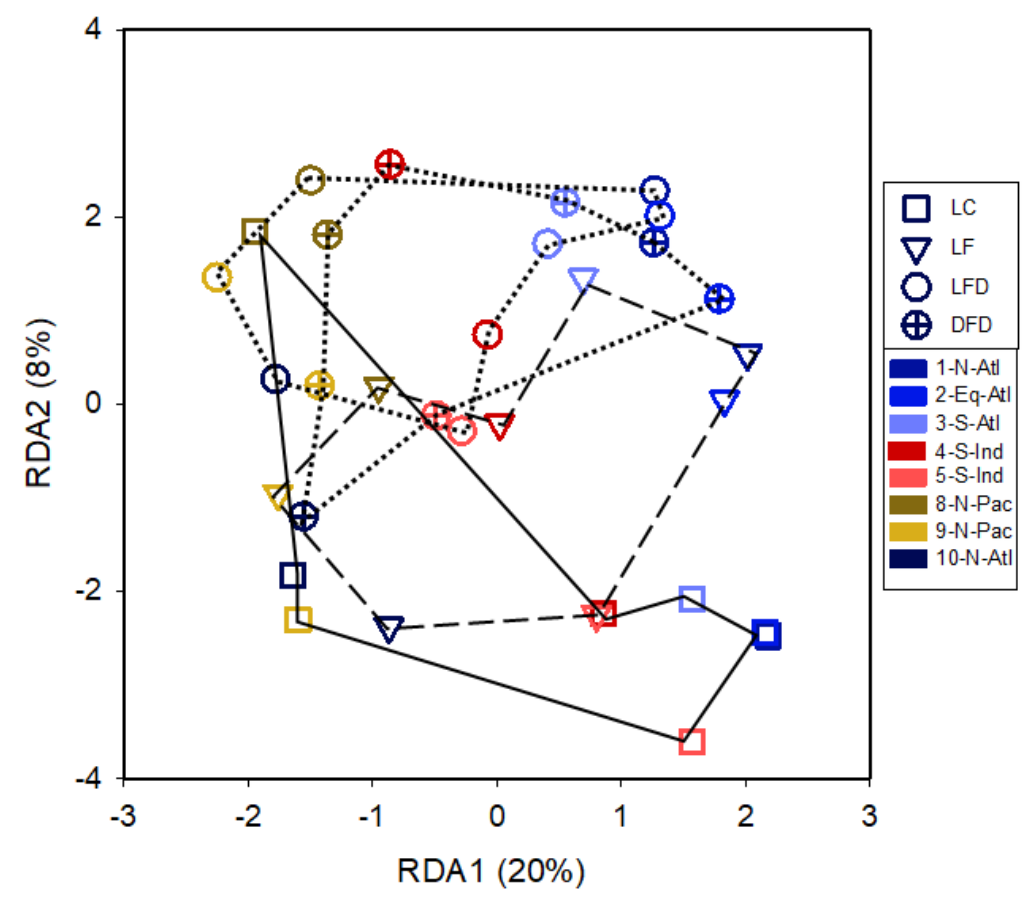

This article is protected by copyright. All rights reserved. 


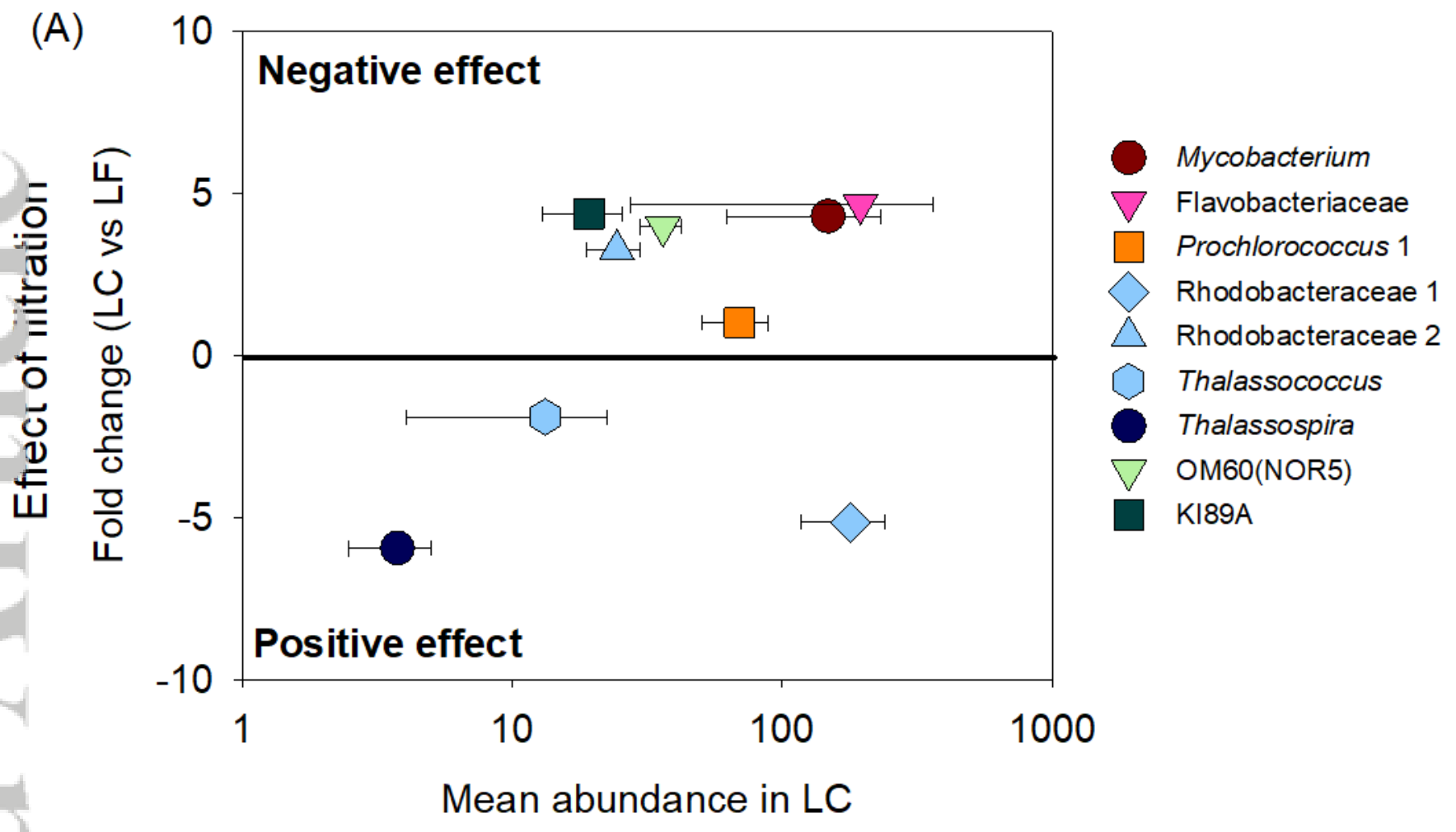

(B)

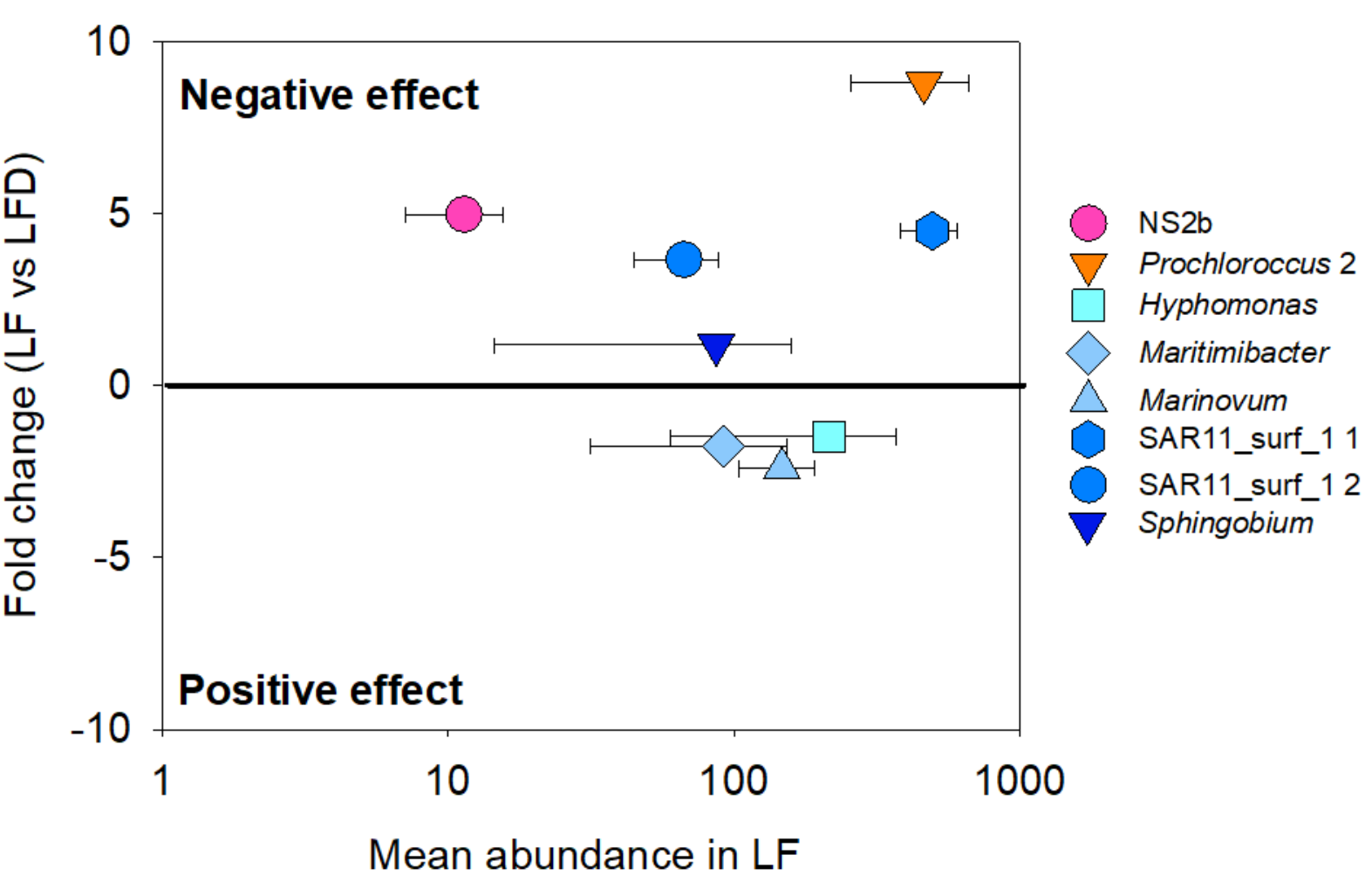

